\title{
Ação de bioestimulantes no desempenho do cultivo de soja em duas condições de adubação fosfatada
}

\section{Action biostimulants performance of soybean under two phosphorus fertilization}

\author{
Valdere Martins dos Santos ${ }^{1}$, Dione Pereira Cardoso ${ }^{2}$, Eduardo Assunção Ferreira $^{3}$, Átila Reis da Silva , Daniele de Cássia \\ Vieira de Sousa $5^{5}$
}

Resumo: Objetivou avaliar a ação de bioestimulantes sobre características agronômicas e produtividade para a cultura da soja, em condições de baixa e alta dose de fósforo. $\mathrm{O}$ delineamento experimental utilizado foi o de blocos casualizados, com quatro repetições, sendo três bioestimulantes e uma testemunha. As características avaliadas foram às características agronômicas (AP = altura de planta; AIV = altura de inserção da 1a vagem; NVP = número de vagem por planta; NSP = número de sementes por plantas; e PCS = pesos de cem sementes) e a produtividade (PROD). Os ambientes com altas doses de fósforo proporcionaram os maiores valores de AP $(70,3 \mathrm{~cm})$, NVP $(138,8)$, NSP $(301,5)$ e PROD $(2868,76 \mathrm{~kg}$ ha-1). Quanto às características AIV e PCS, no ambiente com alta dose de fósforo, não houve diferença estatística entre os tratamentos. Os melhores valores de AP, NVP e NSP são obtidos nos tratamentos T11 e T12, enquanto para PROD, no T13, em ambos os tratamentos destaca-se o bioestimulante, BU-EC. A alta dose de fósforo influencia as variáveis AP, NVP, NSP e PROD, entretanto, as doses de fósforo não influenciam as variáveis AIV e PSC.

Palavras-chave: doses de fósforo, características agronômicas, produtividade.

\begin{abstract}
This study aimed to evaluate the action of biostimulants on agronomic characteristics and yield for soybean, in low and high phosphorus level. The experimental design was a randomized complete block with four replications, with three biostimulants and a witness. The characteristics were evaluated for agronomic traits $(\mathrm{PH}=$ plant height, HPI $=$ height of first pod insertion; NPP = number of pods per plant, NSP = number of seeds per plant, and WHS = weight of one hundred seeds and PROD = Productivity). Environments with high levels of phosphorus gave higher values of PH (70.3 cm), NPP (138.8), NSP (301.5) and PROD (2868.76 kg ha-1). Regarding the characteristics HPI and WHS, the environment with a high dose of phosphorus, there was no statistical difference between treatments. The best values of PH, NPP and NSP are obtained in treatments T11 and T12, while for PROD at T13 in both treatments highlight the biostimulant, BU-EC. The high dose of phosphorus influences the variables PH, NPP, PROD and NSP, however, the phosphorus levels do not influence the variables HPI and WHS.
\end{abstract}

Keywords: phosphorus levels, agronomic characteristics, productivity.

\footnotetext{
*Autor para correspondência

Recebido para publicação em 13/03/2015; aprovado em: 02/07/2015

${ }^{1}$ Universidade Federal do Tocantins/Mestre em Produção Vegetal. E-mail: valderemartins25@ @otmail.com

${ }^{2}$ Universidade Federal do Tocantins/Bolsista de Prodoc. E-mail: cardoso.dione@gmail.com

${ }^{3}$ Universidade Federal do Tocantins/Engenheiro Agrônomo. E-mail: eduardo.ferreira@ nitralurbana.com.br

${ }^{4}$ Universidade Federal de Goiás/Doutor em Solos. E-mail: atilareis@gmail.com

${ }^{5}$ Universidade Federal do Tocantins/Estudante de Agronomia. E-mail: daniele.de@ hotmail.com
} 


\section{INTRODUÇÃO}

A cultura da soja, Glycine max (L.) Merrill, tem grande importância no sistema de produção brasileiro e mundial. No Brasil, essa cultura ocupa posição de destaque e se apresenta como a mais importante cultura em produção de grãos e em exportação (KLAHOLD et al., 2006).

Em muitas regiões do Brasil suas produtividades médias obtidas ainda estão aquém do seu real potencial produtivo, pois os recordes de produção situam-se em torno de 6000 a $7000 \mathrm{~kg} \mathrm{ha}^{-1}$, esses recordes de produção são obtidos através de um conjunto de práticas culturais que visam adequar o ambiente a cultura da soja (DARIO et al., 2005).

Atualmente, alguns bioestimulantes vêm sendo utilizados em diversas culturas de interesse econômico se buscando incrementar suas produtividades, esses produtos podem ser definidos como a mistura de dois ou mais reguladores vegetais ou as misturas desses com outras substâncias (aminoácidos, nutrientes, vitaminas) (ARAÚJO et al., 2010, VIEIRA \& CASTRO, 2003).

Os bioestimulantes contêm substâncias naturais ou sintéticas com diferentes composições, concentrações e proporções, que podem ser aplicadas diretamente nas plantas, em sementes e no solo, com a finalidade de incrementar a produção, melhorar a qualidade de sementes, estimular o desenvolvimento radicular, aumentando a absorção de água e nutrientes pelas raízes, podendo favorecer também o equilíbrio hormonal da planta e germinação mais rápida e uniforme, podem interferir no desenvolvimento vegetal, estimular a divisão, a diferenciação e o alongamento celular, pois, contêm também na sua composição, análogos sintéticos de auxina, giberelina e citocinina (ALBRECHT et al., 2009, SILVA et al., 2008).

Verifica-se que os reguladores influenciam a resposta de muitos órgãos da planta, mas essa resposta depende da espécie, da parte da planta, do estádio de desenvolvimento, da concentração, da interação entre os outros reguladores e vários fatores ambientais (CAMPOS et al., 2008).

Atualmente observa-se uma grande variação nos resultados obtidos, como nos trabalhos de Klahold et al. (2006), Ávila et al. (2008) e Campos et al. (2008), em soja, que observaram que os bioestimulantes podem influenciaram a germinação e a biomassa da matéria seca das sementes, promovem o crescimento das plantas em altura, mas também observaram resposta negativa à aplicação de bioestimulante para as variáveis altura de plantas, massa seca de folhas e número de vagens por planta. Dourado Neto et al. (2004) e Ferreira et al. (2007), em milho, observaram que o tratamento de sementes com Stimulate ${ }^{\circledR}$ e com o fertilizante Cellerate ${ }^{\circledR}$ não afeta a produtividade de grãos; Alleoni et al. (2000) em feijão observou que a utilização de bioestimulantes favoreceu alguns parâmetros produtivos da cultura como peso de 100 sementes e produtividade; Vieira e Santos (2005) e Albrecht et al. (2009) em algodão, observaram que os bioestimulantes podem aumentar a porcentagem de emergência das plântulas, aumentar a velocidade de crescimento radicular, originar plântulas de algodoeiro mais vigorosas, com maior comprimento, massa seca e aumentaram significativamente a produtividade, o rendimento de fibra e a uniformidade das fibras, não sendo fitotóxicas as plantas.

Apesar das pesquisas realizadas faltam mais resultados com relação a real eficiência desses produtos em condições ambientes variadas. Segundo Bertolin et al. (2010) ainda se sabe muito pouco sobre alguns aspectos fisiológicos da planta da soja, relacionados à aplicação de reguladores vegetais, sendo que poucos trabalhos abordam esse assunto. Informações relevantes sobre o efeito destes produtos na cultura da soja forneceriam elementos fundamentais para estudos posteriores sobre a utilização agronômica dos reguladores vegetais.

Baseado no fato de a agricultura está em constante processo de geração de novos conhecimentos, buscando, através da pesquisa, conhecer as causas dos efeitos do uso de diferentes substâncias para a obtenção de maior eficiência na produção agrícola, objetivou com este trabalho avaliar a ação de bioestimulantes sobre características agronômicas e produtividade da cultura da soja, em condições de baixo e alto teor de fósforo.

\section{MATERIAL E MÉTODOS}

\section{Descrição da área experimental}

O experimento foi conduzido na estação experimental da Fundação Universidade Federal do Tocantins - campus de Gurupi, localizado a $11^{\circ} 43^{\prime} 45^{\prime \prime} \mathrm{S}$ e $49^{\circ} 04^{\prime} 07^{\prime} \mathrm{W}$, com altitude média de 287 metros. A análise química da camada superficial $(0-20 \mathrm{~cm})$ foi realizada no Laboratório de Solos, Campus de Gurupi. No laboratório, foram determinados: o pH em água $(4,9)$, os macronutrientes $\left(\mathrm{P}=3,5 \mathrm{mg} \mathrm{dm}^{-3}, \mathrm{~K}^{+}=\right.$ $16,2 \mathrm{mg} \mathrm{dm}^{-3}, \mathrm{Ca}^{2+}=1,2 \mathrm{cmol}_{\mathrm{c}} \mathrm{dm}^{-3} \mathrm{e} \mathrm{Mg}^{2+}=0,3 \mathrm{cmol}_{\mathrm{c}} \mathrm{dm}$ ${ }^{3}$ ), os parâmetros de fertilidade $\left(\mathrm{Al}^{3+}=0,2 \mathrm{cmol}_{\mathrm{c}} \mathrm{dm}^{-3}, \mathrm{H}^{+}+\right.$ $\mathrm{Al}^{3+}=3,8 \mathrm{cmol}_{\mathrm{c}} \mathrm{dm}^{-3}, \mathrm{SB}=1,5 \mathrm{cmol}_{\mathrm{c}} \mathrm{dm}^{-3}, \mathrm{~T}=5,4 \mathrm{cmol}_{\mathrm{c}}$ $\mathrm{dm}^{-3}$ e V $\left.=28,4 \%\right)$ e a matéria orgânica $\left(7,8 \mathrm{~g} \mathrm{dm}^{-3}\right)$.

\section{Instalação do experimento}

O delineamento experimental utilizado foi o de blocos casualizados, com quatro repetições. As parcelas foram constituídas por quatro fileiras com 5,0 m de comprimento, espaçadas de 0,45 m. Para as avaliações utilizou-se uma área útil de $5,4 \mathrm{~m}^{2}$, em que foram consideradas apenas as duas fileiras centrais.

$\mathrm{O}$ experimento foi desenvolvido em dois ambientes. No ambiente I, alta dose de fósforo foi aplicado $100 \mathrm{~kg} \mathrm{P}_{2} \mathrm{O}_{5}$ por hectare. No ambiente II, baixa dose de fósforo foi aplicado 20 $\mathrm{kg} \mathrm{P}_{2} \mathrm{O}_{5}$ por hectare. Sendo utilizado nos dois ambientes como fonte de fósforo o adubo Super Triplo, os demais nutrientes foram aplicados de acordo com a análise química do solo e exigências nutricionais da cultura. Ao solo foi aplicado, como corretivo, calcário dolomítico (PRNT 98\%) na proporção de $2000 \mathrm{~kg} \mathrm{ha}^{-1}$, na adubação de plantio foi aplicado $80 \mathrm{~kg} \mathrm{de}$ $\mathrm{K}_{2} \mathrm{O}$, utilizando como fonte o adubo Cloreto de Potássio. No preparo do solo foi utilizada uma aração e duas gradagens e a semeadura foi feita em sulcos.

As sementes foram submetidas à inoculação com Bradyrhizobium, específico para sementes de soja, na dose de $250 \mathrm{~g}$ por $60 \mathrm{~kg}^{-1}$ de sementes. Realizou-se a semeadura no dia 07.01.2010, com a P98Y70 na densidade de oito sementes por metro. O desbaste foi realizado aos 20 dias após a emergência das plântulas. A irrigação foi realizada utilizando o sistema de irrigação por aspersão convencional. Os aspersores utilizados eram da marca Naan, modelo 233, com dois bocais de $3,9 \mathrm{~mm} \times 2,5 \mathrm{~mm}$ e vazão de $1,31 \mathrm{~m}^{3} / \mathrm{h}$ sob pressão de serviço de $250 \mathrm{kPa}$, no espaçamento de $15 \mathrm{~m} \mathrm{x}$ 
$15 \mathrm{~m}$, que proporciona intensidade de aplicação de 5,82 $\mathrm{mm} \cdot \mathrm{h}^{-1}$.

Não ocorreram doenças que pudessem comprometer o ensaio, e no controle das lagartas ocorrentes na cultura foram realizadas aplicações de Decis na dose de $1 \mathrm{~mL}$ para litro de água, a cada 20 dias após a emergência. As plantas infestantes foram controladas através da aplicação em pós-emergência do herbicida Glifosato, na dose de 2,5 $\mathrm{L} \mathrm{ha}^{-1}$ aos 10 dias após emergência.

Os tratamentos foram constituídos por três bioestimulantes (BU-RG, BU-EC e BU-VG), utilizados de forma isolada e em diferentes combinações (Tabela 1), e uma testemunha não tratada (controle). Os produtos foram utilizados em três formas de aplicação: I, em tratamento de sementes TS, BU-RG e BU-EC, realizado no dia 07.01.2010, momentos antes da semeadura, na dosagem de $100 \mathrm{ml}$ de cada produto para cada $50 \mathrm{Kg}^{-1}$ de sementes; II, em pulverização foliar, BU-EC e BU-VG, no dia 10.02.2010, aos 33 dias após a emergência das plântulas (DAE), quando as mesmas encontravam-se no estádio V3, na dosagem de 800 $\mathrm{ml} \mathrm{ha}{ }^{-1}$ do produto BU-VG e $200 \mathrm{ml} \mathrm{ha}^{-1}$ do produto BU-EC. III, em pulverização foliar no dia 27.03.2010, BU-EC e BUVG, no início do florescimento das plantas, na mesma dosagem que no estádio V3.

Tabela 1. Relação dos tratamentos avaliados e produtos comerciais BU-RG, BU-VG e BU-EC, doses em mL do produto comercial por hectare $\left(\mathrm{L} \mathrm{ha}^{-1}\right)$ ou L $100 \mathrm{~kg}^{-1}$. Gurupi-TO, 2011.

\begin{tabular}{|c|c|c|}
\hline Trat. & +2 & Dose $\mathbf{m L ~ h a}{ }^{-1}$ \\
\hline T1 & BU-RG ${ }^{(1)}$ & 100 \\
\hline $\mathrm{T} 2$ & BU-VG ${ }^{(2)}$ & 800 \\
\hline $\mathrm{T} 3$ & BU-VG ${ }^{(3)}$ & 800 \\
\hline $\mathrm{T} 4$ & BU-EC ${ }^{(1)}$ & 100 \\
\hline T5 & BU-EC ${ }^{(2)}$ & 200 \\
\hline T6 & $\mathrm{BU}-\mathrm{EC}^{(3)}$ & 200 \\
\hline $\mathrm{T} 7$ & Testemunha & - \\
\hline $\mathrm{T} 8$ & $\mathrm{BU}-\mathrm{RG}^{(1)}+\mathrm{BU}-\mathrm{VG}^{(2)}+\mathrm{BU}-\mathrm{VG}^{(3)}$ & $100+800+800$ \\
\hline T9 & $\mathrm{BU}-\mathrm{EC}^{(1)}+\mathrm{BU}-\mathrm{EC}^{(2)}+\mathrm{BU}-\mathrm{EC}^{(3)}$ & $100+200+200$ \\
\hline $\mathrm{T} 10$ & $\mathrm{BU}-\mathrm{RG}^{(1)}+\mathrm{BU}-\mathrm{EC}^{(2)}+\mathrm{BU}-\mathrm{VG}^{(3)}$ & $100+200+800$ \\
\hline $\mathrm{T} 11$ & $\mathrm{BU}-\mathrm{RG}^{(1)}+\mathrm{BU}-\mathrm{EC}^{(2)}+\mathrm{BU}-\mathrm{EC}^{(3)}$ & $100+200+200$ \\
\hline $\mathrm{T} 12$ & $\mathrm{BU}-\mathrm{RG}^{(1)}+\mathrm{BU}-\mathrm{VG}^{(2)}+\mathrm{BU}-\mathrm{EC}^{(3)}$ & $100+800+200$ \\
\hline $\mathrm{T} 13$ & $\mathrm{BU}-\mathrm{EC}^{(1)}+\mathrm{BU}-\mathrm{VG}^{(2)}+\mathrm{BU}-\mathrm{VG}^{(3)}$ & $100+800+800$ \\
\hline
\end{tabular}

${ }^{(1)}$ Em tratamento de sementes

(2) Pulverização foliar, as plantas encontravam-se no o estádio V3

(3) Pulverização foliar, as plantas encontravam-se no inicio do florescimento.

Os bioestimulantes utilizados no tratamento de sementes foram aplicados diretamente sobre as sementes com o auxílio de uma pipeta graduada, antes do plantio. Para tal, as sementes foram acondicionadas em sacos plásticos transparentes com capacidade de $3,0 \mathrm{~kg}$ que foram agitados vigorosamente durante dois minutos. As sementes ficaram em contato com os produtos durante um período de 1 hora. Os bioestimulantes utilizados no estádio V3 e no florescimento, foram aplicados utilizando-se um pulverizador costal com capacidade de $20 \mathrm{~L}$, dotado de um bico JD - 12P, com um gasto de calda equivalente a $150 \mathrm{~L} \mathrm{ha}^{-1}$.

Quando as plantas entraram no estádio R8, ou seja, quando $95 \%$ das vagens apresentavam a coloração típica de vagem madura (Fehr et al., 1971), foram efetuadas as seguintes determinações: altura da planta (AP), altura de inserção da primeira vagem (AIPV), número de vagens por planta (NVP), numero de semente por planta (NSP), peso de 100 sementes (PSC), e produtividade (PROD).

Para a determinação da altura das plantas e altura da inserção da $1^{\text {a }}$ vagem, foram avaliadas 3 plantas, escolhidas ao acaso na área útil das parcelas, realizando a medição com o auxílio de régua milimetrada, sendo os resultados expressos em centímetros. $\mathrm{O}$ número de vagens por planta e o número de sementes por planta, foram avaliados por meio da contagem manual do número de vagens e sementes presentes nas mesmas 3 plantas escolhidas aleatoriamente na área útil de cada parcela.

As plantas foram colhidas manualmente, cinco a oito dias após o estádio de desenvolvimento R8. Em seguida, as sementes foram debulhadas das vagens em máquina trilhadora estacionária, limpas com o auxílio de peneiras, secas em condições naturais e acondicionadas em sacos de papel kraft. Partindo-se do rendimento de sementes nas parcelas, foram calculadas as produtividades em $\mathrm{kg} \mathrm{ha}^{-1}$, para cada tratamento. Em seguida, foi determinado o peso de cem sementes, por meio da pesagem das amostras de cada repetição de campo, com o auxílio de balança analítica com precisão de um miligrama.

\section{Características dos bioestimulantes}

\section{a) BU-RG}

O BU-RG é um bioestimulante do sistema radicular tem como principais características promover um bom desenvolvimento do sistema radicular, garantir um bom crescimento da parte aérea da planta e assegurar um bom rendimento produtivo dos cultivos. Sua composição contém aminoácidos, sulfatos de $\mathrm{Zn}$ e Mn, citrato de Fe, ácido bórico, molibdato de amônio e citrato de ferro.

b) BU-EC

O BU-EC é um bioestimulante formulado a base de extrato de algas marinhas (Ascophyllum nodosum), molibdênio e ácido fosforoso para estimular o desenvolvimento de frutos e corrigir carências de molibdênio. $\mathrm{O}$ extrato de algas composto de fitohormônios naturais como auxinas, citocininas e giberelinas aumentam a fertilidade de gemas produtivas. As algas marinhas podem ser usadas na agricultura na forma de extratos, sendo usadas como fertilizantes bioestimulantes e/ou fitoprotetores, Indução de Resistência Natural (IRN). Os extratos de algas marinhas 
atuam na indução de resistência, sendo muito usado em manejo integrado de doenças.

\section{c) BU-VG}

Fertilizante orgânico obtidos por fermentação biológica natural através de bactéria do gênero Brevibacterium sp. Produto de origem vegetal desenvolvido depois de vários anos de pesquisas. Ativador e Potencializador orgânico. Aminoácido a base de glúten de milho e arroz.

\section{Análise estatística}

Após a obtenção dos dados, realizou-se a análise de variância individual, sendo realizada posteriormente a análise conjunta dos ensaios que apresentaram homogeneidade de variância. Após comparou-se as médias pelo Skott \& Knott a 5\% de probabilidade. Utilizou-se o Programa Genes (Cruz, 2006) para efetuar as análises estatísticas.

\section{RESULTADOS E DISCUSSÃO}

Na tabela 2, observa-se o resumo das análises de variância das características. Foram observadas diferenças significativas nas características altura da planta, número de vagens por planta, número de sementes por planta e produtividade.

Tabela 2. Resumo das análises de variância das características altura da planta (AP), altura da inserção de primeira vagem (AIP), número de vagem por planta (NVP), número de semente por planta (NSP), peso de cem sementes (PSC) e produtividade (PROD) de cultivar de soja, em função da aplicação de bioestimulantes em duas condições de adubação fosfatada. Gurupi-TO.

\begin{tabular}{cccccccc}
\hline \multirow{2}{*}{ FV } & \multirow{2}{*}{ GL } & \multicolumn{6}{c}{ Quadrado Médio } \\
\cline { 3 - 7 } & & AP & AIV & NVP & NSP & PSC & PROD \\
\hline Bloco/Amb. & 6 & 9,90 & 1,99 & 253,60 & 427,29 & 0,39 & 38143,87 \\
Tratamento & 12 & $19,48^{* *}$ & 6,24 & $1430,21^{* *}$ & $6487,83^{* *}$ & 0,83 & $363945,91^{* *}$ \\
Ambiente & 1 & $5013,73^{* *}$ & $157,78^{* *}$ & $69940,47^{* *}$ & $233227,16^{* *}$ & 0,87 & $6924152,48^{* * *}$ \\
Trat. x Amb. & 12 & $33,53^{* *}$ & 5,97 & $734,26^{* *}$ & $2304,23^{* *}$ & 0,77 & $177452,87^{* *}$ \\
Resíduo & 72 & 10,28 & 3,89 & 161,93 & 635,66 & 0,67 & 47985,46 \\
\hline CV (\%) & & 5,061 & 9,43 & 11,32 & 9,91 & 5,81 & 8,39 \\
\hline
\end{tabular}

= F significativo a $1 \%$ de probabilidade pelo teste $\mathrm{F}$.

Para a característica altura de planta (AP) verificou-se que o ambiente com alta dose de fósforo proporcionou maiores valores de altura de plantas (AP) que o ambiente com baixa dose de fósforo, com valor de 70,3 cm, contra $56,4 \mathrm{~cm}$, da baixa dose de fósforo (Tabela 3). Na alta dose de fósforo o tratamento T3 obteve a maior altura de planta 73,08 (cm), diferindo somente dos tratamentos T4, T10 e T13, com alturas de plantas de 68,33; 66,48; 31,6415 (cm), respectivamente. $\mathrm{Na}$ baixa dose de fósforo os tratamentos $\mathrm{T} 1$ e T2 obtiveram as maiores alturas 68,04 e $66,57 \mathrm{~cm} \mathrm{planta}^{-1}$, respectivamente. Comparando se as médias dos tratamentos independentemente dos ambientes, observa-se que o tratamento T1 obteve a maior altura de plantas $(68,04 \mathrm{~cm})$, enquanto o tratamento T13 obteve o menor valor $58,53 \mathrm{~cm}$.

Tabela 3. Médias de altura da planta (AP) e altura de inserção da $1^{\text {a }}$ vagem (AIV), em resposta à aplicação de bioestimulantes, em dois ambientes (alto e baixo teores de fósforo) para a cultura da soja. Gurupi-TO, 2010.

\begin{tabular}{|c|c|c|c|c|c|c|}
\hline \multirow[t]{2}{*}{ Trat. } & \multicolumn{3}{|c|}{$\mathbf{A P}$} & \multicolumn{3}{|c|}{ AIV } \\
\hline & $\begin{array}{l}\text { Alta dose de } \\
\text { fósforo }\end{array}$ & Baixa dose de fósforo & MG & $\begin{array}{l}\text { Alta dose de } \\
\text { fósforo }\end{array}$ & $\begin{array}{l}\text { Baixa dose de } \\
\text { fósforo }\end{array}$ & MG \\
\hline 1 & 72,18 a $\mathrm{A}$ & 63,90 a B & $68,04 a$ & 22,40 a $\mathrm{A}$ & 22,10 a $\mathrm{A}$ & 22,25 a \\
\hline 2 & 71,98 a A & 61,18 a B & $66,57 a$ & 24,08 a A & 19,35 a B & 21,71 a \\
\hline $\begin{array}{l}3 \\
4\end{array}$ & $\begin{array}{l}73,08 \text { a A } \\
68,33 \text { b A }\end{array}$ & $\begin{array}{l}56,58 \text { b B } \\
59,68 \text { b B }\end{array}$ & $\begin{array}{c}64,83 a \\
64,0 a\end{array}$ & $\begin{array}{l}20,78 \text { a A } \\
21,75 \text { a A }\end{array}$ & $\begin{array}{l}18,18 \text { a A } \\
20,43 \text { a A }\end{array}$ & $\begin{array}{l}19,47 \text { a } \\
21,08 \text { a }\end{array}$ \\
\hline 5 & 72,83 a $\mathrm{A}$ & $55,68 \mathrm{c} \mathrm{B}$ & $64,25 a$ & 22,23 a A & 19,75 a $\mathrm{A}$ & 20,98 a \\
\hline 6 & 71,08 a $\mathrm{A}$ & $51,58 \mathrm{c} \mathrm{B}$ & $61,33 b$ & 22,33 a $A$ & 18,93 a B & 20,63 a \\
\hline 7 & 69,75 a $A$ & 51,68 с B & $60,71 b$ & 23,43 a $\mathrm{A}$ & 20,35 a B & 21,88 a \\
\hline 8 & 70,18 a $\mathrm{A}$ & $54,08 \mathrm{c} \mathrm{B}$ & $62,13 b$ & 20,85 a $\mathrm{A}$ & 20,08 a $A$ & $20.46 a$ \\
\hline 9 & 71,08 a A & 52,70 c B & 61,88b & 24,08 a A & 17,43 a B & 20,75a \\
\hline 10 & 66,48 b A & 58,43 b B & $62,45 b$ & 21,43 a $A$ & 20,18 a $\mathrm{A}$ & $20,80 a$ \\
\hline 11 & 71,00 a $\mathrm{A}$ & 57,18 b B & $64,08 a$ & 21,75 a $\mathrm{A}$ & 19,68 a $\mathrm{A}$ & 20,71a \\
\hline 12 & 71,68 a $\mathrm{A}$ & $57,68 \mathrm{~b} \mathrm{~B}$ & $64.67 a$ & 22,93 a $A$ & 20,90 a $\mathrm{A}$ & 21.91a \\
\hline 13 & $64,15 \mathrm{~b} \mathrm{~A}$ & 52,93 с B & $\mathbf{5 8 , 5 3 b}$ & 20,00 a A & 18,65 a $\mathrm{A}$ & $19.32 \mathrm{a}$ \\
\hline MA & $70,29 A$ & $56,40 \mathrm{~B}$ & & $22,15 \mathrm{~A}$ & $19,69 A$ & \\
\hline
\end{tabular}

Médias seguidas pelas mesmas letras minúsculas na VERTICAL e maiúsculas na HORIZONTAL constituem grupo estatisticamente homogêneo pelo teste Skott \& Knott a 5\% de probabilidade. MG - Média geral. MA - Média de Ambiente.

Observa-se com relação a essa característica que no ambiente alta dose de fósforo os bioestimulantes não promoveram um maior crescimento nas plantas de soja. Resultados esses semelhantes ao encontrados por Albrecht et al. (2011) que ao avaliarem o biorregulador Stimulate ${ }^{\circledR}$ no desempenho agronômico de plantas soja, bem como os componentes da produção, não observaram efeito significativo na característica altura de plantas. Porém no ambiente baixa dose de fósforo houve incrementos significativos em alguns dos tratamentos em que foram aplicados os bioestimulantes, sendo que para essa característica os produtos se mostraram mais eficiente em condições de estresse ambiental. Segundo Vasconcelos (2006) plantas cultivadas em ambientes favoráveis 
conseguem expressar todo o seu potencial produtivo, fazendo com que muitas vezes que os efeitos dos bioestimulantes não sejam facilmente expressados, mas quando as mesmas são conduzidas em condições de estresse ambiental, se e possível observar com mais facilidade os efeitos dos bioestimulantes como ocorreu nesse trabalho, pois as maiores vantagens da utilização desses produtos estar no fato dos mesmos poderem aumentar a absorção de água e nutrientes pelas plantas, bem como sua resistência aos estresses hídricos e aos efeitos de herbicidas no solo.

Os maiores desenvolvimentos em altura observados em alguns dos tratamentos em que foram aplicados os bioestimulantes também estão relacionados á presença de giberelina nos bioestimulantes, a giberelina e um hormônio vegetal que apresentam função associada à promoção do crescimento caulinar, de forma que plantas submetidas a aplicações de giberelinas podem ser induzidas a obter um maior crescimento na sua estatura (TAIZ \& ZEIGLER, 2009).

Quanto à altura de inserção da $1^{\text {a }}$ vagem (AIV), não se observou diferença estatística entre os ambientes (Tabela 3). No ambiente alta dose de fósforo, mesmo não havendo diferença estatística entre os tratamentos, os tratamentos T2 e T9 obtiveram os maiores valores com alturas de inserção da $1^{\text {a }}$ vagem (AIV), de $(24,08 \mathrm{~cm})$. Resultados esses semelhantes aos encontrados por Albrecht et al. (2011). Sabe se que para a realização da colheita mecânica são necessários plantas de soja com ponto de inserção das primeiras vargens igual ou superior a $10 \mathrm{~cm}$, mas cultivares com altura de primeira vagem maior que 15 a $20 \mathrm{~cm}$ facilitam a colheita e apresentam menores perdas, de forma que os dados obtidos nesse trabalho foram superiores aos valores mínimos indicados pela literatura mesmo em condições de baixa dose de fósforo.

Em relação ao número de vagem por planta (NVP), verificou-se diferença estatística entre os ambientes (Tabela 4). No ambiente alta dose de fósforo foi obtido 138,3 vagens por planta, e no ambiente baixa dose de fósforo, 86,4 vagens por planta. No ambiente alta dose de fósforo o tratamento T13 obteve o maior número de vagem por planta, 170 vagens, enquanto a testemunha, tratamento T7 obteve o menor valor 114 vagem por planta. $\mathrm{Na}$ baixa dose de fósforo os tratamentos T12 e T13 obtiveram os maiores números de vagens por planta 105 cada. Comparando os tratamentos nos dois ambientes observa-se que o tratamento T13 obteve o maior valor 137,5 vagens por planta, enquanto a testemunha, tratamento $\mathrm{T} 7$ obteve o menor valor 92 vagens por planta.

Tabela 4. Médias de número de vagem por planta (NVP) e número de sementes por planta (NSP), em resposta à aplicação de produtos bioestimulantes, em dois ambientes (alto e baixo teores de fósforo) para a cultura da soja. Gurupi-TO, 2010.

\begin{tabular}{|c|c|c|c|c|c|c|}
\hline \multirow[b]{2}{*}{ Trat. } & \multicolumn{3}{|c|}{ NVP } & \multicolumn{3}{|c|}{ NSP } \\
\hline & $\begin{array}{l}\text { Alta dose de } \\
\text { fósforo }\end{array}$ & $\begin{array}{l}\text { Baixa dose de } \\
\text { fósforo }\end{array}$ & MG & $\begin{array}{l}\text { Alta dose de } \\
\text { fósforo }\end{array}$ & $\begin{array}{l}\text { Baixa dose de } \\
\text { fósforo }\end{array}$ & MG \\
\hline 1 & $117.25 \mathrm{c} \mathrm{A}$ & 90.00 a B & $103.62 \mathrm{~b}$ & $255.00 \mathrm{c} \mathrm{A}$ & $207.25 \mathrm{~b} \mathrm{~B}$ & $231.13 \mathrm{~b}$ \\
\hline 2 & 139,25 b A & 82,50 b B & $110.87 \mathrm{~b}$ & 321,50 a $A$ & $196,50 \mathrm{c} \mathrm{B}$ & 259,00 a \\
\hline 3 & $127,00 \mathrm{~b} \mathrm{~A}$ & 93,50 a $\mathrm{B}$ & $110,25 \mathrm{~b}$ & 269,75 с A & $210,00 \mathrm{~b} \mathrm{~B}$ & $239,87 \mathrm{~b}$ \\
\hline 4 & $142,50 \mathrm{~b} \mathrm{~A}$ & 72,75 b B & 107,62 b & 338,50 a $\mathrm{A}$ & 236,00 a B & 287,25 a \\
\hline 5 & $119,25 \mathrm{c} \mathrm{A}$ & $84,25 \mathrm{~b} \mathrm{~B}$ & $101,75 \mathrm{~b}$ & 280,75 b A & $217,50 \mathrm{~b} \mathrm{~B}$ & $249,12 \mathrm{~b}$ \\
\hline 6 & 147,75 a A & 101,50 a B & 124,62 a & 334,25 a $\mathrm{A}$ & 204,75 b B & 269,50 a \\
\hline 7 & $114,00 \mathrm{c} \mathrm{A}$ & $70,00 \mathrm{~b} \mathrm{~B}$ & $92,00 \mathrm{~b}$ & $256,50 \mathrm{cA}$ & $158,25 \mathrm{c} \mathrm{B}$ & 207,37 c \\
\hline 8 & 165,50 a $A$ & 77,50 b B & $121,50 \mathrm{a}$ & 339,00 a $A$ & 181,50 c B & 260,25 a \\
\hline 9 & $135,25 \mathrm{~b} \mathrm{~A}$ & 59,75 b B & $97,50 \mathrm{~b}$ & $249,50 \mathrm{c} \mathrm{A}$ & 165,75 с B & 207,62 c \\
\hline 10 & $132,25 \mathrm{~b} \mathrm{~A}$ & 77,75 b B & $105,00 \mathrm{~b}$ & 298,50 b A & 186,00 с B & 242,25 b \\
\hline 11 & 157,50 a $\mathrm{A}$ & 104,25 a B & 130.87 a & 335,00 a $\mathrm{A}$ & 232,00 a B & 283,50 a \\
\hline 12 & $130,50 \mathrm{~b} \mathrm{~A}$ & 105,00 a B & $117.75 \mathrm{a}$ & 290,00 b A & 246,75 a B & 268.37 a \\
\hline 13 & 170,00 a A & 105,00 a B & $137,50 \mathrm{a}$ & 351,75 a $\mathrm{A}$ & 246,50 a B & 299,12 a \\
\hline MA & 138,31 A & 86,44 B & & $301,54 \mathrm{~A}$ & 206,83 B & \\
\hline
\end{tabular}

Médias seguidas pelas mesmas letras minúsculas na VERTICAL e maiúsculas na HORIZONTAL constituem grupo estatisticamente homogêneo pelo teste Skott \& Knott a 5\% de probabilidade. MG - Média geral. MA - Média de Ambiente.

Resultados esses semelhantes aos encontrados por Bertolin et al. (2010), que ao avaliarem a produção de grãos de soja em função da aplicação do Bioestimulante Stimulate ${ }^{\circ}$, que é composto por três hormônios vegetais: $0,009 \%$ de cinetina, 0,005\% de ácido giberélico e 0,005\% de ácido indolbutírico, constataram que o bioestimulante aumentou o número de vagens por planta e produtividade de grãos tanto em aplicação via sementes quanto via foliar. Albrecht et al. (2011), também observou efeito significativo na característica número de vagens por planta, demostrando a eficiência agronômica do uso de bioreguladores. O número de vagem por planta (NVP) é uma característica de grande importância para os produtores, pois a mesma esta intimamente relacionada com a produtividade final da cultura.

Segundo Carvalho et al. (2002), ao se aumentar o número de nós por planta e, por consequência, o número de vagens, é possível alcançar maiores produtividades, já que tais parâmetros são usados na seleção de genótipos para elevadas produtividades.

Contudo Dario et al. (2005), avaliaram diferentes doses de citocinina, ácido indol- butílico e ácido giberélico, que compõem o fitorregulador (Stimulate $\AA)$, não encontraram influencia significativa sobre número de vagens por plantas. Sendo que os resultados contraditórios encontrados em alguns trabalhos podem estar relacionados ao fato de que bons resultados com a aplicação de produtos de ação bioestimulantes dependem de uma de uma série de fatores, desde a região a espécie da planta, até situações como o processo de absorção do produto, associado com a condição da planta, equipamentos e os métodos de aplicação, influenciados pelas condições do ambiente. Por serem produtos que atuam em concentrações muito baixas, qualquer alteração pode modificar o efeito esperado (SEVERINO et al., 2003; MONTANS, 2006). 
Quanto à característica número de sementes por planta (NSP) (Tabela 4), observou-se diferença estatística entre os ambientes e entre os tratamentos. O ambiente com alta dose de fósforo proporcionou maiores valores de NSP $(301,5)$ que o ambiente com baixa dose de fósforo $(206,8)$. No ambiente alta dose de fósforo o tratamento T8 obteve o maior número de sementes por planta 339,00, enquanto o tratamento T9 obteve o menor número de sementes por planta 249,50 . Na baixa dose de fósforo o tratamento T12 obteve o maior número de sementes por plantas 246,75. Comparando os tratamentos nos dois ambientes observa-se que o tratamento T13 obteve o maior valor de sementes por planta $(299,12)$, enquanto a testemunha, tratamento T7 obteve o menor valor $(207,37)$.

Klahold et al. (2006), avaliaram o efeito do bioestimulante, Stimulate ${ }^{\circledR}$, aplicado via semente e pulverização foliar, na cultura da soja, concluíram que a aplicação do bioestimulante proporcionou incremento, no número de grãos e na produção por planta, na cultura da soja.

Em relação aos resultados obtidos de peso de cem sementes (PCS), também não se observou diferença estatística entre os resultados (Tabela 5). Resultado semelhante ao encontrado por Albrecht et al. (2011), que não observou efeito significativo na vaiável massa de 1.000 sementes.

Tabela 5. Médias de peso de cem sementes (PCS) e produtividade (PROD), em resposta à aplicação de produtos bioestimulantes, em dois ambientes (alta dose de fósforo e baixa dose de fósforo) para a cultura da soja. Gurupi-TO, 2010.

\begin{tabular}{|c|c|c|c|c|c|c|}
\hline \multirow[t]{2}{*}{ Trat. } & \multicolumn{3}{|c|}{ PCS } & \multicolumn{3}{|c|}{ PROD } \\
\hline & $\begin{array}{l}\text { Alta dose de } \\
\text { fósforo }\end{array}$ & $\begin{array}{l}\text { Baixa dose de } \\
\text { fósforo }\end{array}$ & MG & $\begin{array}{c}\text { Alta dose de } \\
\text { fósforo }\end{array}$ & $\begin{array}{l}\text { Baixa dose de } \\
\text { fósforo }\end{array}$ & MG \\
\hline 1 & $14 . .13$ a $\mathrm{A}$ & $14 . .58$ a A & $14 . .35 \mathrm{a}$ & $3146 . .90$ a A & $2921 . .20$ a A & $3034 . .05$ a \\
\hline 2 & 13,83 a $\mathrm{A}$ & 14,30 a $\mathrm{A}$ & $14,06 \mathrm{a}$ & 2815,18 b A & 2630,65 b A & 2722,91 a \\
\hline 3 & 14,33 a $\mathrm{A}$ & $14,53 \mathrm{a} A$ & $14,43 \mathrm{a}$ & 3270,18 a $\mathrm{A}$ & 2321,73 с B & 2795,95 a \\
\hline 4 & 12,88 a A & 14,03 a A & 13,45 a & $2842,38 \mathrm{~b} \mathrm{~A}$ & 2305,03 с B & 2573,70 b \\
\hline 5 & 14,15 a $A$ & $13,58 \mathrm{a} A$ & 13.86 a & 2891,23 b A & 2213,50 с B & 2552.36 b \\
\hline 6 & 14,13 a $A$ & 14,05 a A & $14,08 \mathrm{a}$ & 2807,85 b A & 2330,63 с B & $2569,24 \mathrm{~b}$ \\
\hline 7 & $14.05 \mathrm{a} \mathrm{A}$ & $13,50 \mathrm{aA}$ & $13.78 \mathrm{a}$ & $2560.63 \mathrm{c} \mathrm{A}$ & $1857.98 \mathrm{~d} B$ & $2209.30 \mathrm{~b}$ \\
\hline 8 & 14,85 a $\mathrm{A}$ & $13,65 \mathrm{a} \mathrm{A}$ & $14,25 \mathrm{a}$ & 2470,18 с A & 2195,13 c B & 2332.65 b \\
\hline 9 & 14,75 a $\mathrm{A}$ & 14,23 a $\mathrm{A}$ & 14,48 a & 2916,68 b A & 2267,98 с B & 2592,33 b \\
\hline 10 & 14,13 a $\mathrm{A}$ & 13,88 a A & $14,00 \mathrm{a}$ & 3033,53 a A & 2563,38 b B & 2798,45 a \\
\hline 11 & $14,53 \mathrm{a} A$ & $14,08 \mathrm{a} A$ & $14.30 \mathrm{a}$ & 3111,78 a $\mathrm{A}$ & 2111,13 с B & 2611.45 b \\
\hline 12 & $14,65 \mathrm{a} \mathrm{A}$ & 14,43 a $\mathrm{A}$ & $14,54 \mathrm{a}$ & 2421,73 с A & 2455,15 b B & 2438,44 b \\
\hline 13 & $14.85 \mathrm{a} \mathrm{A}$ & $14.05 \mathrm{aA}$ & $14.45 a$ & 3005.65 a A & 2411.68 c B & $2708.66 \mathrm{a}$ \\
\hline MA & $14.25 \mathrm{~A}$ & $14.07 \mathrm{~A}$ & & $2868.76 \mathrm{~A}$ & 2352.70 B & \\
\hline
\end{tabular}

Médias seguidas pelas mesmas letras minúsculas na VERTICAL e maiúsculas na HORIZONTAL constituem grupo estatisticamente homogêneo pelo teste SKOTT \& KNOTT a 5\% de probabilidade. MG - Média geral. MA - Média de Ambiente.

Quanto à produtividade (PROD), o ambiente com alta dose de fósforo proporcionou valor significativamente maior $\left(2868,76 \mathrm{~kg} \mathrm{ha}^{-1}\right)$, que o ambiente com baixa dose de fósforo $\left(2352,70 \mathrm{~kg} \mathrm{ha}^{-1}\right.$ ) (Tabela 5). No ambiente alta dose de fósforo os tratamentos T1 e T3 obtiveram as maiores produtividade de grãos (3146,90 e $3270,17 \mathrm{~kg} \mathrm{ha}^{-1}$ respectivamente), enquanto o tratamento T12 obteve o menor valor $(2421,73 \mathrm{~kg}$ $\left.\mathrm{ha}^{-1}\right)$. Na baixa dose de fósforo a maior produtividade foi obtida no tratamento T1, com 2921,20 kg ha ${ }^{-1}$. Enquanto o tratamento T7, a testemunha obteve o menor valor $1857,98 \mathrm{~kg}$ $\mathrm{ha}^{-1}$. Comparando as médias dos tratamentos independentemente dos ambientes observa-se que o tratamento $\mathrm{T} 1$ obteve o maior valor $3034,05 \mathrm{~kg} \mathrm{ha}^{-1}$, enquanto a testemunha, tratamento T7, obteve o menor valor $(2209,30$ $\left.\mathrm{kg} \mathrm{ha}^{-1}\right)$.

Observa se que os tratamentos T1 e T2 na baixa dose de fósforo, obtiveram valores estatisticamente iguais em comparação a alta dose de fósforo. Contudo, esses tratamentos apresentaram valores superiores à testemunha, tratamento T7 em alta dose de fósforo. Já o tratamento T10, em baixa dose de fósforo apresentou diferença estatística com relação aos demais tratamentos em alta dose de fósforo, mas também apresentou produtividade maior que testemunha (T7), $2563.38 \mathrm{Kg} \mathrm{ha}^{-1}$.

Resultados semelhantes aos encontrados por Mortele et al. (2008), que avaliaram o efeito da aplicação de biorregulador Stimulate ${ }^{\circledR}$ no desempenho agronômico das plantas e na produtividade de sementes da cultura da soja, em dois anos agrícolas 2005/06 e 2006/07, obtiveram produtividade de sementes de $2927 \mathrm{~kg} \mathrm{ha}^{-1}$ no ano agrícola 2005/06. No segundo ano agrícola 2006/07, não houve diferença significativa $(\mathrm{P}>0,05)$ entre os tratamentos na produtividade de sementes. No primeiro ano agrícola, 2005/06, porém, a cultura sofreu com um estresse hídrico prolongado, mas observou se que não houve diferença significativa $(\mathrm{P}>0,05)$ entre os tratamentos na produtividade de sementes em ambos os anos agrícolas estudados.

Segundo os autores a partir dos resultados obtidos é possível inferir que um dos princípios básicos para melhorar a eficácia do biorregulador na cultura da soja foi à condição climática adversa, ou seja, a ocorrência de veranico no primeiro ano em estudo, com isso pode se supor que a efetividade do biorregulador é mais pronunciada e apresenta melhores resultados quando há uma condição de estresse, como a seca que ocorreu no primeiro ano agrícola. Resultados esses que corroboram com os encontrados neste trabalho, em que ocorreu uma condição adversa no ambiente baixa dose de fósforo neste caso a deficiência de fósforo, confirmando que um dos princípios básicos para melhorar a eficácia do biorregulador na cultura da soja é a condição climática adversa.

Albrecht et al. (2009), avaliaram o uso de biorregulador , via tratamento de semente a aplicação foliar na cultua do algodão, e observaram baixa produtividade média, obtida pela testemunha, em seu trabalho. Segundo os autores, esse resultado supostamente ocorreu em virtude das condições climáticas desfavoráveis observadas no decorrer do desenvolvimento da cultura, que se caracterizaram por um período de estiagem. O mesmo foi mais evidente no mês de dezembro de 2005 e início de janeiro de 2006, conforme 
observado nos resultados de balanço hídrico. Essas mesmas condições de estresse que desencadearam baixo rendimento da testemunha, ocasionado por um "strain" plástico (como queda das estruturas reprodutivas) (TAIZ \& ZEIGER, 2009), proporcionaram a expressão dos efeitos benéficos da aplicação do biorregulador Stimulate ${ }^{\circledR}$ na cultura, apresentando comprovado efeito atenuador sobre os efeitos do estresse ambiental.

Quando as plantas se desenvolvem sob condições de estresse, os radicais livres ou espécies de oxigênio (superóxido, radicais hidroxila, peróxido de hidrogênio) danificam as células das plantas. De forma que com a utilização de produtos bioestimulantes se e possível incremental os níveis de antioxidantes nas plantas e com isso aumentar o sistema de defesa das mesmas. Os antioxidantes em maiores níveis nas plantas estão diretamente relacionados ao maior crescimento radicular e da parte área, mantendo um alto conteúdo de água nas folhas (VASCONCELOS, 2006).

Vieira \& Castro (2001) usando produto composto por reguladores vegetais de ação promotora verificaram na cultura da soja, plantas com sistemas radiculares mais desenvolvidos, apresentando raízes mais vigorosas com valores de massa seca, crescimento e comprimento total superiores aos encontrados nas plantas não tratadas.

Os bioestimulantes utilizados no tratamento de sementes neste trabalho têm como principais características promover um bom desenvolvimento do sistema radicular. Plantas com sistema radicular bem desenvolvido conseguem uma melhor e maior exploração dos recursos disponíveis no solo, como água e nutrientes minerais. Observar-se que em condições adversas os bioestimulantes conseguem propiciar bom resultados, pelo fato de fornecer melhores condições de adaptação as plantas a ambientes adversos, aspecto que certamente influi positivamente na produtividade da cultura.

Outro ponto importante a se discutir neste trabalho foi o fato do mesmo ter sido desenvolvido em duas condições de adubação fosfatada, sendo obtidos bons resultados em ambos os ambientes. Sabe-se que os solos tropicais do Brasil apresentam baixa dose de fósforo disponível e reação ácida, cujas características, aliadas às altas taxas de adsorção do fósforo, têm sido consideradas as limitações mais severas na utilização desses solos e no aumento da produtividade das culturas, fazendo com que haja a necessidade de aplicações de altas doses de fósforo. Ressalta-se, ainda, que os fosfatos são recursos naturais não renováveis, escassos devendo, portanto, ter utilização eficaz (ARAÚJO et al., 2008; LEÃO et al., 2007). De forma que com a utilização dos bioestimulantes utilizados neste trabalho pode-se utilizar solos com menor teor de $\mathrm{P}$ para a agricultura, bem como reduzir a possíveis adubações fosfatadas.

Com os resultados encontrados nesse trabalho observar-se que a utilização de produtos bioestimulantes tornar-se uma opção interessante para a cultura da soja, tanto em condições ideais de cultivo, bem como em condições de estresse ambiental, tendo em que vista que os bioestimulantes promoveram um maior desenvolvimento das plantas de soja na fase inicial da cultura, o que favoreceu o estabelecimento da mesma no campo e consequentemente a obtenção de maiores produtividades.

Portanto, o uso de bioestimulantes, é passível de serem recomendados para uso na cultura da soja, focando na elevação no número de vagem por plantas e na produtividade.

\section{CONCLUSÕES}

Os melhores valores de AP, NVP e NSP são obtidos nos tratamentos T11 (BU-RG + BU-EC + BU-EC) e T12 (BU-RG + BU-VG + BU-EC), enquanto para PROD, no T13 (BU-EC + BU-VG + BU-VG), em ambos os tratamentos destaca-se o bioestimulante, BU-EC. Para as características avaliadas AIV e PCS, não há diferença entre os tratamentos.

A alta dose de fósforo influencia as variáveis $\mathrm{AP}, \mathrm{NVP}$, NSP e PROD, entretanto, os teores de fósforo não influenciam as variáveis AIV e PSC.

\section{REFERÊNCIAS BIBLIOGRÁFICAS}

ALBRECHT, L.P.; BRACCINI, A.L.; ÁVILA, M.R.; BARBOSA, M.C.; RICCI, T.T.; ALBRECHT, A.J.P. Aplicação de biorregulador na produtividade do algodoeiro e qualidade de fibra. Scientia Agraria, v.10, p.191-198, 2009.

ALBRECHT, L.P.; BRACCINI, A.L.; SCAPIM, C.A.; ÁVILA, M.R.; ALBRECHT, A.J.P.; RICCI, T.T. Manejo de biorregulador nos componentes de produção e desempenho das plantas de soja. Bioscience Journal, v.27, p.865-876, 2011.

ALLEONI, B.; BOSQUEIRO, M.; ROSSI, M. Efeito dos reguladores vegetais de Stimulate no desenvolvimento e produtividade do feijoeiro (Phaseolus vulgaris L.). Publicatio UEPG, v.6, p.23-35, 2000.

ARAÚJO, F.F.; TIRITAN, C.S.; PEREIRA, H.M.; CAETANO JÚNIOR, O. Desenvolvimento do milho e fertilidade do solo após aplicação de lodo de curtume e fosforita. Revista Brasileira de Engenharia Agrícola e Ambiental, v.12, p.507-511, 2008.

ÁVILA, M.R.; BRACCINI, A.L.; SCAPIM, C.A.; ALBRECHT, L.P.; TONIN, T.A.; STÜLP, M. Bioregulator application, agronomic efficiency, and quality of soybean seeds. Scientia Agricola, v.65, p.567-691, 2008.

BERTOLIN, D.C.; SÁ, M.E.; ARF, O.; FURLANI JUNIOR, E.; COLOMBO, A.S.; CARVALHO, F.L.B.M. Aumento da produtividade de soja com a aplicação de bioestimulantes. Bragantia, v.69, p.339-347, 2010.

CAMPOS, M.F.; ONO, E.O.; BOARO, C.S.F.; RODRIGUES, J.D. Análise de crescimento em plantas de soja tratadas com substâncias reguladoras. Revista Biotemas, v.21, p.53-63, 2008.

CARVALHO, C.G.P.; ARIAS, C.A.A.; TOLEDO, J.F.F.; OLIVEIRA, M.F.; VELLO, N.A. Correlação e análise de trilha em linhagens de soja semeadas em diferentes épocas. Pesquisa Agropecuária Brasileira, v.37, p. 311-320, 2002.

CRUZ, C.D. Programa Genes: Biometria. Viçosa: Editora UFV, 2006. 382p.

DARIO, G.J.A.; MARTIN, T.N.; DOURADO NETO, D.; MANFRON, P.A.; BONNECARRÈRE, R.A.G.; CRESPO, P.E.N. Influência do uso de fitorregulador no crescimento da soja. Revista da FZVA, v.12, p. 63-70, 2005. 
DOURADO NETO, D.; DARIO, G.J.A.; VIEIRA JUNIOR, P.A.; MANFRON, P.A.; MARTIN, T.N.; GARCIA, R.A. Aplicação e influência do fitorregulador no crescimento das plantas de milho. Revista da FZVA, v.11, p.1-9, 2004.

FEHR, W.R.; CAVINESS, C.E; GURMOOD, D.T.; PENNINGTON, J.S. Stage of development description for soybean, Glycine max (L.) Merrill. Crop Science, v.11, p.929-931, 1971.

FERREIRA, L.A.; OLIVEIRA, J.A.; VON PINHO, É.V.R.; QUEIROZ, D.L. Bioestimulante e fertilizante associados ao tratamento de sementes de milho. Revista Brasileira de Sementes, v.29, p.80-89, 2007.

KLAHOLD, C.A.; GUIMARÃES, V.F.; ECHER, M.M.; KLAHOLD, A.; ROBINSON, L.C., BECKER, A. Resposta da soja (Glycine max (L.) Merrill) à ação de bioestimulante. Acta Scientiarum. Agronomy, v.28, p.179-185, 2006.

LEÃO, A.B.; ANDRADE, A.R.S.; CHAVES, L.H.G.; CHAVES, I.B.; GUERRA, H.O.C. Variabilidade espacial de fósforo em solo do perímetro irrigado Engenheiro Arcoverde, PB. Revista Ciência Agronômica, v.38, p.1-6, 2007.

MONTANS, F.M.; COSTA, A.F.; ALVES, A.L.G.; MENDES, F.C.; GUIMARÃES, A.M.; OLIVEIRA, P.S.R.; LEITE, S.M.M. Inoculação e aplicação de regulador vegetal na cultura do amendoim cultivados em dois tipos de solo. In: VII Simpósio de Iniciação Científica \& III Encontro de Pós-graduação, 2006, Marília. Anais do $7^{\circ}$ Simpósio de Iniciação Científica e $3^{\text {o }}$ Encontro de Pós-graduação. Marília: Universidade de Marília, 2006.

MOTERLE, L.M.; SANTOS, R.F.; BRACCINI, A.L.; SCAPIM, C.A.; BARBOSA, M.C. Efeito da aplicação de biorregulador no desempenho agronômico e produtividade da soja. Acta Scientiarum. Agronomy, v.30, p.701-709, 2008.

SANTOS, C.M.G.; VIEIRA, E.L. Efeito de bioestimulante na germinação de sementes, vigor de plântulas e crescimento inicial do algodoeiro. Magistra, v.17, p.124-130, 2005.

SEVERINO, L.S.; LIMA, C.L.D. de; FARIAS V. de A.; BELTRÃO, N.E. de M.; CARDOSO, G.D. 2003. Aplicação de regulador de crescimento em sementes de algodão, amendoim, gergelim e mamona. Boletim de Pesquisa e Desenvolvimento (53). Embrapa, Centro Nacional de Pesquisa de Algodão.

SILVA, T.T.A.; PINHO, É.R.V.; CARDOSO, D.L.; FERREIRA, C.A.; ALVIM, P.O.; COSTA, A.A.F. Qualidade fisiológica de sementes de milho na presença de bioestimulantes. Ciência Agrotecnologia, v.32, p.840-846, 2008.

TAIZ, L.; ZEIGER, E. Fisiologia vegetal. 4. ed. Porto Alegre: Artmed, 2009. 819p.

VASCONCELOS, A.C.F. Uso de Bioestimulantes nas Culturas de Milho e Soja. 2006. 112p. Tese (Doutorado em Agronomia. Área de Concentração: Solos e Nutrição de Plantas) Escola Superior de Agricultura Luís de Queiroz, Universidade de São Paulo.

VIEIRA, E.L.; CASTRO, P.R.C. Ação de bioestimulante na germinação de sementes, vigor de plântulas, crescimento radicular e produtividade de soja. Revista Brasileira de Sementes, v.23, p.222-228, 2001.

VIEIRA, E.L.; SANTOS, C.M.G. Efeito de bioestimulante no crescimento e desenvolvimento inicial de plantas de algodoeiro. Magistra, v.17, p.1-8, 2005. 